\title{
Central nervous system failure in melanoma patients: results of a randomised, multicentre phase 3 study of temozolomide- and dacarbazine- based regimens
}

\section{Chiarion-Sileni*, , M Guida ${ }^{2}$, L Ridolfi ${ }^{3}$, A Romanini ${ }^{4}$, P Del Bianco ${ }^{5}$, J Pigozzo', S Brugnara ${ }^{6}$, G Colucci ${ }^{2}$, R Ridolfi ${ }^{3}$ and GL De Salvo ${ }^{5}$ for the Italian Melanoma Intergroup (IMI)}

'Melanoma and Skin Cancer Unit, Istituto Oncologico Veneto IOV - IRCCS, via Gattamelata 64, Padova 35 I 28, Italy; ${ }^{2}$ Department of Medical Oncology, Istituto Oncologico, via Hahnemann 10, Bari 70 126, Italy; ${ }^{3}$ Immunotherapy and Somatic Cell Therapy Unit, Istituto Scientifico Romagnolo per lo Studio e la Cura dei Tumori, via Maroncelli 40, Meldola FC 47014, Italy; ${ }^{4}$ Medical Oncology Unit, S. Chiara Hospital, via Roma 67, Pisa 56 I00, Italy; ${ }^{5}$ Clinical Trials and Biostatistics Unit, Istituto Oncologico Veneto IOV - IRCCS, via Gattamelata 64, Padova 35I 28, Italy; ${ }^{6}$ Oncology Center, S. Chiara Hospital, Largo Medaglie d'Oro I, Trento 38100, Italy

BACKGROUND: This study compared the central nervous system (CNS) metastasis incidence between a temozolomide- and a dacarbazine-based regimen in untreated stage IV melanoma patients.

METHODS: A total of 150 patients were randomly assigned to receive either oral temozolomide $\left(200 \mathrm{mg} \mathrm{m}^{-2}\right.$ per day; days I-5) or intravenous dacarbazine $\left(800 \mathrm{mg} \mathrm{m}^{-2}\right.$; day $\left.\mathrm{I}\right)$, in combination with intravenous cisplatin $\left(75 \mathrm{mg} \mathrm{m}^{-2}\right.$; day I) and subcutaneous interleukin-2 (3 MU twice daily; days 9- I8), every 28 days (CTI and CDI).

RESULTS: A total of 149 patients were eligible for an intention-to-treat analysis (CTI: $n=74, \mathrm{CDI}: n=75)$. The I-year cumulative CNS incidence failure was $20.6 \%$ for CTI and $31.1 \%$ for CDI $(P=0.22)$. In all 24 patients in CTI (32\%) and 34 (45\%) in CDI developed CNS metastases; 31 patients died of early systemic progression, before CNS evaluation. Median survival time was 8.4 months in the CTI and 8.7 in the CDI arm; in patients with CNS metastases the median survival time was I 3.5 months in the CTI and I I.5 in the CDI arm. No difference in toxicity was observed between the two arms.

CONCLUSION: The incidence of CNS failures in metastatic melanoma was not significantly reduced and the clinical course was not modified substituting a dacarbazine-based regimen with a temozolomide-based regimen. Patients who developed CNS metastases did not have a worse prognosis than patients progressing in other sites and should not be excluded from new investigational studies. British Journal of Cancer (201 I) 104, 1816-1821. doi:10.1038/bjc.2011.178 www.bjcancer.com

Published online 24 May 20II

(c) 201 I Cancer Research UK

Keywords: advanced melanoma; brain metastasis; temozolomide; dacarbazine; randomised clinical trial

\begin{abstract}
Melanoma incidence is increasing in Europe as well as in the USA and the prognosis of metastatic disease is very dismal with a median survival of 6-9 months and a 10-year survival of less than $10 \%$ (Bhatia et al, 2009). Visceral metastases through haematogenous dissemination could be ubiquitous and central nervous system (CNS) involvement is quite frequent, reported in up to $46 \%$ of melanoma patients over their lifetime (Barnholtz-Sloan et al, 2004; Houghton et al, 2006). CNS recurrence is the first and often the only site of progression in up to $25 \%$ of responsive patients (Atkins et al, 1999). Melanoma contributes to at least $10 \%$ of all CNS metastases (Wen et al, 2001) and is second only to lung cancer (Barnholtz-Sloan et al, 2004). More than $70 \%$ of patients who develop CNS metastases are diagnosed with multiple symptomatic lesions, excluded from studies with new drugs and treated only with symptomatic care. Therefore, the development of
\end{abstract}

\section{*Correspondence: Dr V Chiarion-Sileni; E-mail: mgaliz@tiscali.it}

Previous presentations: Published as abstract on ASCO Annual meeting proceedings, 2008 - J Clin Oncol 26: 2008 (May 20 suppl; abstr 200 I4) Received 28 January 2011; revised 18 April 2011; accepted 21 April 20I I; published online 24 May $201 \mathrm{I}$
CNS metastases is considered more devastating and debilitating than other visceral metastatic sites. In the early stages of CNS metastasis growth, when the blood-brain barrier (BBB) is still intact, the different permeability of the drugs could be crucial (Gerstner and Fine, 2007). Temozolomide (TMZ) is an oral imidazotetrazine second-generation alkylating agent that has shown some efficacy in metastatic melanoma and is active in primary brain tumours. TMZ has a high oral bio-availability and extensive tissue distribution, including penetration through the $\mathrm{BBB}$ and achievement of therapeutic concentrations in the CNS. A phase III trial showed that TMZ was as safe as, well tolerated and not less active than Dacarbazine (DTIC) (Middleton et al, 2000). Paul et al (2002) first reported a reduction from 43 to $10 \%$ in CNS metastasis incidence in responsive TMZ-treated patients with respect to responsive DTIC-treated patients. Other authors observed a similar effect using combinations in which TMZ replaced DTIC (Atkins et al, 2002; Ridolfi et al, 2004; Ready et al, 2005; Weber et al, 2005; Ron et al, 2006). The combination of TMZ with cisplatin is synergistic in in-vitro through the downregulation of the activity of the DNA repair enzyme $0^{6}$-alkylguanine-DNAalkyltransferase, which mediates the resistance to TMZ. The safety 
of this combination has been tested (Piccioni et al, 1995; D'Atri et al, 2000) in vivo in advanced solid tumours (Britten et al, 1999) and in melanoma.

Interleukin-2 (IL-2) was added to both combinations of cisplatin/DTIC (CDI) and cisplatin/TMZ (CTI) to increase the response rate, the progression-free (PFS) and possibly the overall survival (OS), as this was a common expectation when we planned this study (Eton et al, 2002). This, however, was not confirmed in subsequent studies and in a meta-analysis (Ives et al, 2007).

This phase III study was designed to verify whether the CTI combination significantly reduces or delays the incidence of CNS metastases compared with the CDI combination in metastatic, chemotherapy-naive, melanoma patients.

\section{PATIENTS AND METHODS}

\section{Study design}

The study was designed as a multicenter, randomised, open-label phase III trial. Randomisation was performed centrally at the Clinical Trials and Biostatistics Unit of the Istituto Oncologico Veneto. Treatment was assigned in a $1: 1$ ratio using a minimisation method over four stratification factors: gender, stage (M1a-M1b vs M1c), according to the American Joint Committee on Cancer Staging 2002 (Balch et al, 2001), serum LDH level (normal $v s$ above normal) and centre.

\section{Patient selection}

Patients with histologically or cytologically confirmed stage IV cutaneous melanoma, without evidence of CNS metastases by contrast-enhanced computed tomographic (CT) scan or gadolinium -enhanced magnetic resonance imaging (MRI), were eligible.

Patients had to fulfil the following criteria: age $\geqslant 18$ years, Eastern Cooperative Oncology Group performance status (PS) of $0-2$, a life expectancy of a least 10 weeks and adequate haematological function (absolute neutrophil count $>1500$ per $\mathrm{mm}^{3}$, platelet count $>100000$ per $\mathrm{mm}^{3}$ ), hepatic function (total bilirubinemia $<1.25 \times$ upper limit of normal (ULN), $2.5 \times$ ULN in case of liver metastases), aspartate amino transferase and alanine amino transferase $<2 \times$ ULN $(3 \times$ ULN in case of liver metastases) and renal function (serum creatinine $<110 \mu \mathrm{moll}^{-1}$ ), and no previous malignancies except for adequately treated in situ carcinoma of the cervix or squamous carcinoma of the skin. Patients with uncontrollable angina, heart failure or infectious diseases were not eligible. Previous interferon adjuvant therapy or radiotherapy or isolated hyperthermic limb perfusion were permitted. Local Ethics Review Committee approval was obtained from all participating centres and written informed consent from all patients.

\section{Treatment plan}

Treatment consisted of either CTI or CDI. Cisplatin was administered intravenously at $75 \mathrm{mg} \mathrm{m}^{-2}$ on day 1 , followed by oral TMZ at $200 \mathrm{mg} \mathrm{m}^{-2}$ per day for 5 days in the CTI arm or by intravenous DTIC at $800 \mathrm{mg} \mathrm{m}^{-2}$ on day 1 in the CDI arm. In both arms, patients also received $3000000 \mathrm{IU}$ of subcutaneous IL-2 twice daily from days 9 to 17 ; subcutaneous G-CSF was recommended at a daily dose of $300 \mu \mathrm{g}$ from days 6 to 12 . Treatment cycles were repeated every 28 days if absolute neutrophil count was $>1500$ per $\mathrm{mm}^{3}$, platelet count $>100000$ per $\mathrm{mm}^{3}$ and serum creatinine $<150 \mu \mathrm{moll}^{-1}$; otherwise, chemotherapy was delayed for 1 week. Before and 14 days after each cycle, clinical evaluation, haematology and biochemistry were repeated to evaluate toxicity. Cisplatin was decreased by $50 \%$ if serum creatinine was between 110 and $150 \mu \mathrm{moll}^{-1}$ with a creatinine clearance $>45 \mathrm{ml}$ per min despite sufficient hydration.
Treatment was discontinued if serum creatinine was $>150 \mu \mathrm{moll}^{-1}$ or creatinine clearance $<45 \mathrm{ml}$ per min despite sufficient hydration, or in case of grade 3 neurological toxicity or if the treatment had to be delayed for more than 2 consecutive weeks. TMZ or DTIC were decreased by $25 \%$ in case of grade 4 febrile neutropenia for more than 5 days, or grade 4 non-febrile neutropenia or grade 4 thrombocytopenia for more than 7 days during the previous cycle. This dose reduction was maintained thereafter.

\section{Baseline evaluation and follow-up}

Baseline evaluation included a complete medical history, physical examination, Eastern Cooperative Oncology Group PS, chemistry tests, chest and abdominal CT scan, and cardiologic evaluation in the 30 days before randomisation. Any required laboratory assessment, which resulted abnormal had to be repeated within $48 \mathrm{~h}$ before enrolment. Detection of CNS metastases was carried out by brain CT scan systematically followed by MRI in case of single lesions potentially amenable to surgery or radio-surgery treatment. Complete and differential blood count was assessed every 2 weeks, and chemistry tests every four, during treatment. Chest and abdominal CT scan were repeated every 2 months during treatment, every 3 months in the first year after the end of treatment and every 6 months thereafter. Brain CT scan or MRI was repeated every 4 months during treatment and the first 2 years of follow-up, and every 6 months thereafter. Brain CT scan or MRI was required also at the time of progression.

\section{Response and toxicity criteria}

Toxicity was assessed at each cycle according to the NCI-CTC (version 3.0). Each serious adverse event was fully evaluated and, if drug related, a decision was made as to whether the risk/benefit justified the patient's continuation in the study. Each serious adverse event was reported to the competent authority and the drug producing company. Response was assessed according to the RECIST criteria in all patients who had completed at least one course of treatment. In the case of stable disease (SD) chemotherapy was continued till a maximum of six cycles. Chemotherapy was discontinued in the case of progressive disease (PD), or unacceptable toxicity or patient refusal.

\section{Statistical methods}

On the basis of our previous data (Ridolfi et al, 2002), the 1-year incidence of CNS metastases was expected to be $30 \%$ in the CDI arm. An accrual of 148 patients in 2 years and a further follow-up of 1 year would provide the adequate power (80\%) to detect a $57 \%$ reduction in the instantaneous risk of having CNS metastases, $12 \%$ in the CTI and 30\% in the CDI arm (two-sided test, alpha-level: $5 \%)$. Analysis was performed on an intention to treat basis. In the two arms, patients should be followed until CNS relapse or death and for a follow-up period of at least 1 year.

Time to CNS metastases was the primary endpoint of the study and was defined as the time from randomisation to the radiological occurrence of CNS failure. The cumulative incidence of CNS metastases was estimated using a competing risk analysis, accounting for death resulting from all causes as a competing risk. To compare treatment groups, the Gray's test was used (Gray, 1988).

PFS and OS were analysed as secondary end points. PFS was defined as the time from randomisation to any type of progression or death from any cause. OS was defined as the time from randomisation to death from any cause. Both end points were estimated by means of the Kaplan-Meier method and the log-rank test was used for comparisons. 
To assess safety, the two arms were compared in terms of all grade distribution using the Wilcoxon's rank-sum test. Difference in occurrence of grade 3/4 toxicity events between arms was assessed using the Fisher's exact test.

All $P$-values were based on a two-sided test and statistical analyses were carried out using SAS statistical software (Release 9.1; SAS Institute, Cary, NC, USA).

\section{RESULTS}

\section{Patient characteristics}

From June 2003 to June 2007, 150 patients with unresectable stage IV melanoma were randomly assigned by 12 Italian centres to receive either CTI $(n=75)$ or CDI $(n=75)$ (Figure 1$)$. One patient in the CTI arm was excluded due to CNS metastases at randomisation.

Patients and known prognostic factors were well balanced in the two arms (Table 1). Fifty-three percent of the patients had stage M1c, 29\% had an elevated serum LDH and 32\% had received adjuvant therapy, consisting almost exclusively of high-dose interferon.

\section{CNS failure}

CNS failure was assessable in 118 patients, 57 in the CTI and 61 in the CDI arm. Of the 118 patients, 58 were positive at brain CT scan, 24 in the CTI and 34 in the CDI arm. The remaining 31 patients died after a median period of 3 months before CNS failure evaluation and of these, 13 died before undergoing any instrumental assessment of disease.

Figure 2 shows the cumulative incidence of the CNS metastases among patients treated with CTI and CDI. Death without CNS metastases was considered a competing event. The observed risk of a CNS relapse with CTI was not significantly different to that with CDI $(P=0.22$, Gray's test $)$.

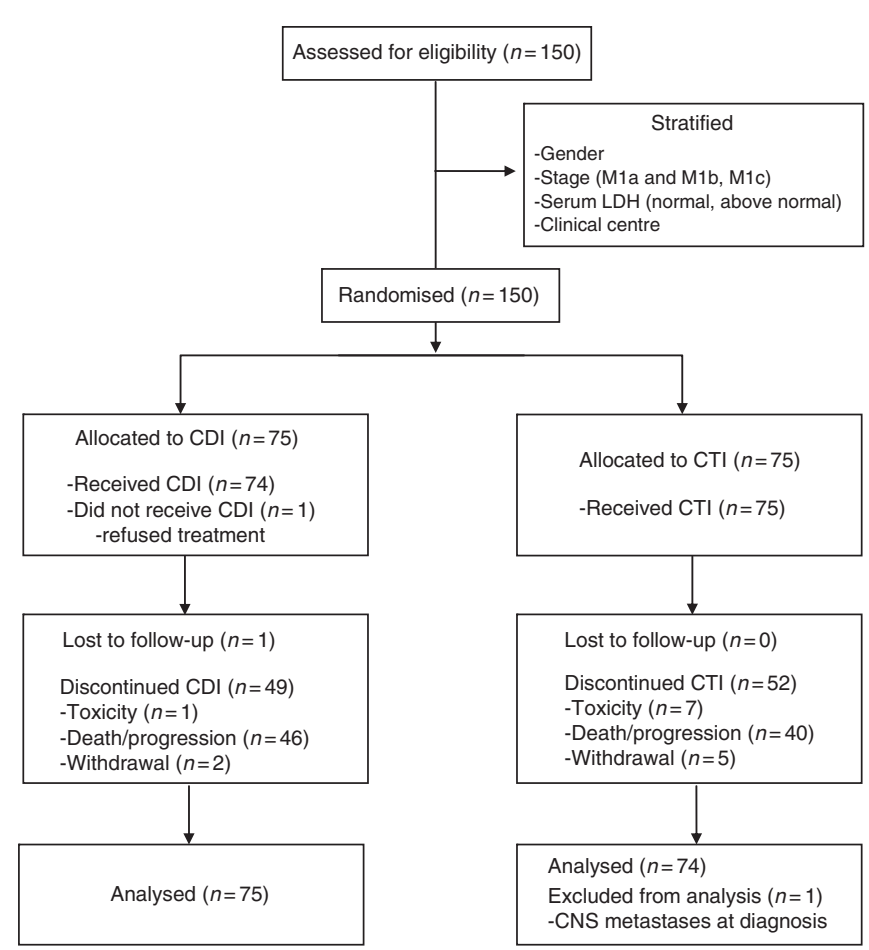

Figure I CONSORT diagram.
The 1-year cumulative CNS failure incidence was $20.6 \%$ for the CTI and $31.1 \%$ for the CDI, and the cause specific hazard ratio (HR) for CTI vs CDI was 0.9 (95\% CI: 0.5, 1.5).

CNS metastases represented the first site of failure for 32 patients (12 in the CTI and 20 in the CDI arm) and for 26 patients the CNS relapse was preceded by a failure in another site.

Ten patients are still alive after a minimum follow-up of 46 months: four with CNS metastases, three with metastases in other sites and three in complete remission.

The clinical characteristics of CNS progressions did not differ in the two arms: 14 patients had a single lesion, six in the CTI and eight in the CDI arm, and 44 had multiple lesions: 18 in the CTI and 26 in the CDI arm.

\section{Response}

The OR rate was $18 \%$ in the CTI and $22 \%$ in the CDI arm $(P=0.73$, $\chi^{2}$-test). Complete remission occurred in 10 patients (7\%), two in

Table I Patient characteristics

\begin{tabular}{lcc}
\hline & $\begin{array}{c}\text { CDI arm } \\
(\mathbf{N}=\mathbf{7 5})\end{array}$ & $\begin{array}{c}\mathbf{C T I} \text { arm } \\
(\mathbf{N}=\mathbf{7 4})\end{array}$ \\
\hline Age, years & $54.5(23-74)$ & $51.2(23-74)$ \\
Sex & & \\
$\quad$ Male & $46(61 \%)$ & $45(61 \%)$ \\
Female & $29(39 \%)$ & $29(39 \%)$ \\
ECOG-PS & & \\
0 & $52(69 \%)$ & $51(69 \%)$ \\
I & $15(20 \%)$ & $17(23 \%)$ \\
2 & $3(4 \%)$ & $3(4 \%)$ \\
Not reported & $5(7 \%)$ & $3(4 \%)$ \\
Disease site & & $35(47 \%)$ \\
$\quad$ Mla-MIb & $35(47 \%)$ & $39(53 \%)$ \\
MIc & $40(53 \%)$ & $21(28 \%)$ \\
LDH level & & $53(72 \%)$ \\
$\quad$ Abnormal & $23.2(0-159.7)$ \\
Normal & $22(29 \%)$ & \\
Time from diagnosis to & $53(71 \%)$ & \\
metastatic disease, months & $32.3(1.8-164.9)$ & \\
\hline
\end{tabular}

Abbreviations: $\mathrm{CDI}=\mathrm{DT} \mid \mathrm{C}$-based chemotherapy; $\mathrm{CTI}=\mathrm{TMZ}$-based chemotherapy DTIC = Dacarbazine; ECOG-PS = Eastern Cooperative Oncology Group performance status; $\mathrm{LH}=$ lactate dehydrogenase; $\mathrm{TMZ}=$ Temozolomide. Data are N (\%) or median (range)

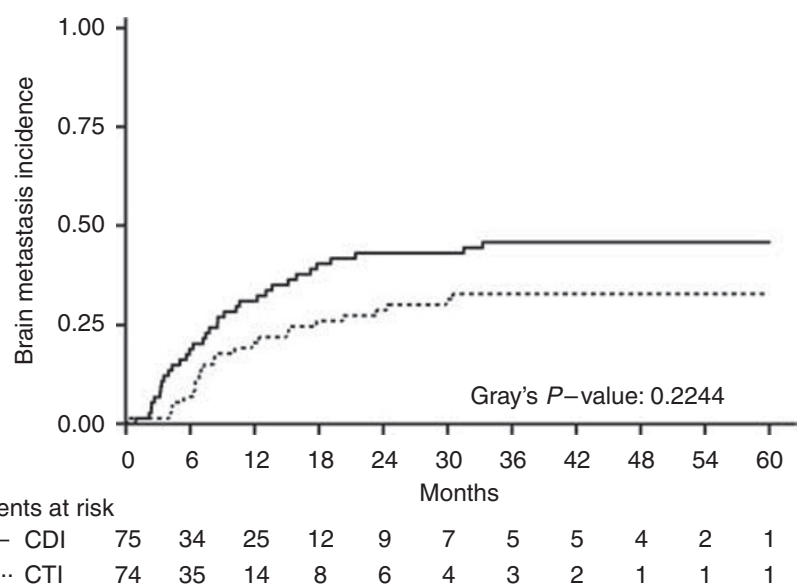

Figure 2 Cumulative incidence function of central nervous system failure of patients receiving TMZ-based chemotherapy (CTI) and DTIC-based chemotherapy (CDI). 


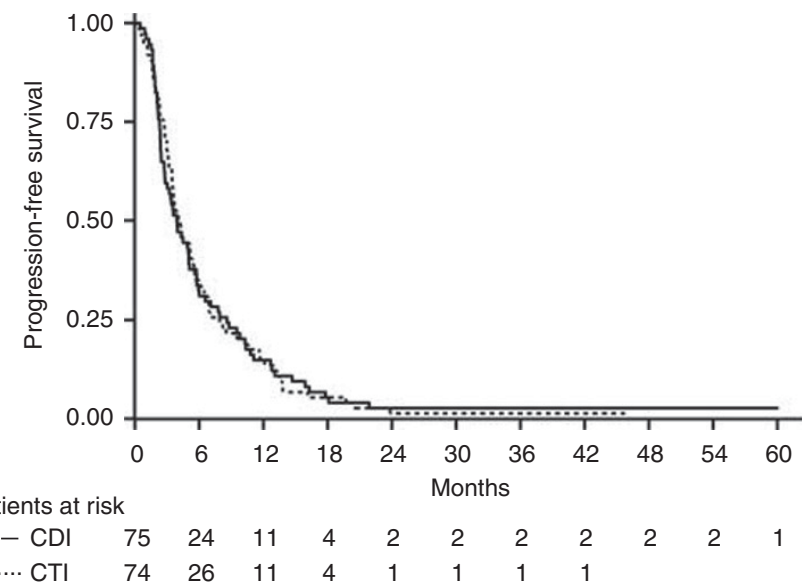

Figure 3 Kaplan-Meier curves for progression-free survival of patients receiving TMZ-based chemotherapy $(\mathrm{CTI})$ and DTIC-based chemotherapy $(\mathrm{CDI})$

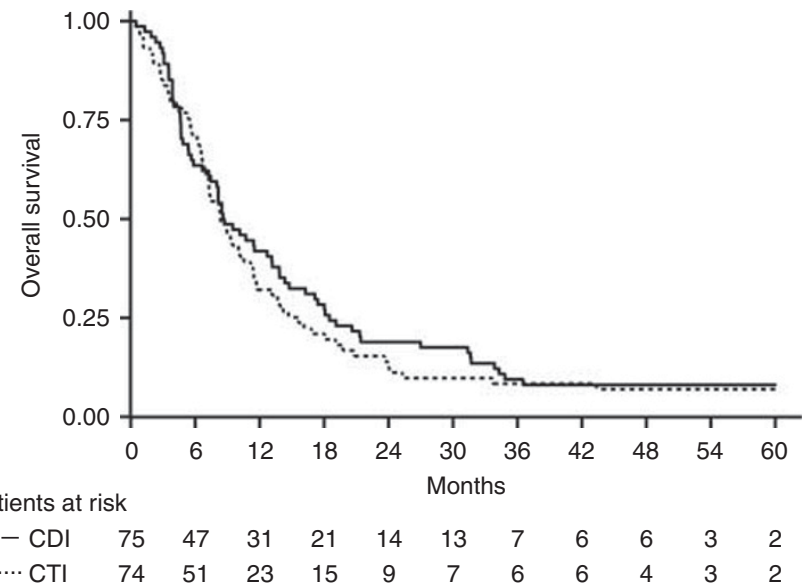

Figure 4 Kaplan-Meier curves for overall survival of patients receiving TMZ-based chemotherapy (CTI) and DTIC-based chemotherapy (CDI).

the CTI and eight in the CDI arm. An additional 30 patients (20\%), 16 in the CTI and 14 in the CDI arm, presented SD.

The median PFS (Figure 3) was 4.1 months (95\% CI: $3.5-5.4$ ) in the CTI and $3.9(95 \% \mathrm{CI}: 2.8-5.1)$ in the CDI arm $(P=0.90$, log-rank test), and the HR for CTI vs CDI was 1.0 (95\% CI: 0.7, 1.4). The 1-year PFS was $13.7 \%$ (95\% CI: 7.0-22.6) in the CTI and 14.9 (95\% CI: 7.9-23.9) in the CDI arm.

The median OS (Figure 4) was 8.4 months (95\% CI: $7.0-10.5)$ in the CTI and 8.7 (95\% CI: 7.3-13.2) in the CDI arm $(P=0.40$, logrank test), and the HR for CTI vs CDI was 1.2 (95\% CI: 0.8, 1.6). The 1-year OS was $31.2 \%$ (95\% CI: $20.8-42.0)$ in the CTI and $41.9 \%$ (95\% CI: $30.6-52.8$ ) in the CDI arm.

In patients with CNS failure, the median OS was 13.5 months (95\% CI: 9.3-19.1) for the CTI and 11.5 (95\% CI: 8.1-14.4) for the CDI arm (Figure 5, $P=0.25$, log-rank test), and the HR for CTI $v s$ CDI was 0.7 (95\% CI: 0.4,1.3).

\section{Safety}

In the CTI arm, 22 patients $(30 \%)$ completed the planned treatment and 52 stopped earlier, $7(9 \%)$ for toxicity and 45 (61\%) for PD, death or refusal. In the CDI arm, 26 patients (35\%) completed the planned treatment and 49 stopped earlier, 1 for toxicity $(1 \%)$ and $48(64 \%)$ for $\mathrm{PD}$, death or refusal. The mean
Temozolomide impact on melanoma central nervous system failure $\checkmark$ Chiarion-Sileni et al

delivered doses of cisplatin and IL-2 were the same in the two arms: $47 \mathrm{mg} \mathrm{m}^{-2}$ and $30 \mathrm{MU} ; 40$ and 41 patients received G-CSF in the CTI and CDI arm, respectively.

Treatment was carried out almost entirely on an outpatient basis and patients were admitted only for disease palliation. No treatment-related deaths were observed. Haematological and non-haematological toxicities are summarised in Table 2. Haematological and flu-like symptoms were the most frequently observed toxicities in both arms, followed by nausea/vomit and liver enzyme abnormalities. The distribution of all grade toxicity was similar in the two groups, except for anaemia, which was higher in the CTI arm $(P=0.01$, Wilcoxon's rank-sum test $)$.

\section{DISCUSSION}

This is the first prospective study designed to test whether TMZ is able to decrease the incidence and alter the clinical course of CNS metastases in melanoma patients. When we planned this trial in 2001, bio-chemotherapy was still considered a promising approach able to produce objective tumour responses in up to $40 \%$ of treated patients. As a high activity was crucial for the purpose of our study, we chose to compare TMZ and DTIC not alone but in combination with cisplatin and IL-2 (Eton et al, 2002).

The clinical activity observed in the two arms is similar to that published using these combinations (Bafaloukos et al, 2005; Gonzalez Cao et al, 2006; Wierzbicka-Hainaut et al, 2010). The incidence of CNS failure in the CDI arm was as expected and consistent with our previous experience using dacarbazine alone or in combination. Instead, the incidence in the CTI arm was higher than planned and previously published, particularly in responsive patients where it reached $60 \%$. This finding can be explained by the specific design of the study where CNS imaging every 4 months detected asymptomatic CNS metastases in more than $50 \%$ of patients. Neither the incidence of CNS recurrences nor the clinical course of the CNS involvement were significantly influenced by TMZ. In fact, the percentage of single or multiple lesions, as well as the overall survival in patients with CNS relapses and the incidence of CNS failure as first site of metastasis, were similar in the two arms. The significant reduction reported by Paul et al (2002) was observed in a retrospective analysis of different studies where the CNS relapses were not specifically sought-after and the radiological confirmation of clinical suspicion was not mandatory. Likewise, no specific follow-up, aimed at detecting asymptomatic lesions, was reported in the study by Ron et al (2006), where no CNS recurrences were observed in 10 responding 
Table 2 Treatment toxicity

\begin{tabular}{|c|c|c|c|c|c|c|}
\hline & \multicolumn{3}{|c|}{ CDI $\operatorname{arm}(N=74)$} & \multicolumn{3}{|c|}{ CTI $\operatorname{arm}(N=74)$} \\
\hline & All grades & Grade 3 & Grade 4 & All grades & Grade 3 & Grade 4 \\
\hline Fatigue & $45(61 \%)$ & I| (I5\%) & I (I\%) & 43 (58\%) & II (15\%) & $2(3 \%)$ \\
\hline Fever & $38(5 \mid \%)$ & $5(7 \%)$ & - & 40 (54\%) & 7 (9\%) & - \\
\hline Nausea/vomiting & 47 (63\%) & II (I5\%) & - & 44 (59\%) & 7 (9\%) & - \\
\hline Constipation & $8(11 \%)$ & - & - & $9(12 \%)$ & - & - \\
\hline Diarrhoea & $5(7 \%)$ & - & - & $5(7 \%)$ & - & - \\
\hline Anorexia & $15(20 \%)$ & $6(8 \%)$ & - & $17(23 \%)$ & $3(4 \%)$ & I (I\%) \\
\hline Leukocytes & $14(19 \%)$ & I (I\%) & I (I\%) & $21(28 \%)$ & $3(4 \%)$ & $2(3 \%)$ \\
\hline Neutropenia & $28(38 \%)$ & 7 (9\%) & $4(5 \%)$ & $29(39 \%)$ & $10(14 \%)$ & 7 (9\%) \\
\hline Thrombocytopenia & $23(31 \%)$ & $3(4 \%)$ & $2(3 \%)$ & 22 (30\%) & $3(4 \%)$ & $4(5 \%)$ \\
\hline Anaemia & $23(31 \%)$ & $3(4 \%)$ & - & 35 (47\%) & $6(8 \%)$ & I (I\%) \\
\hline Lymphopenia & 7 (9\%) & $2(3 \%)$ & - & $10(14 \%)$ & I (1\%) & $2(3 \%)$ \\
\hline Liver function & $23(31 \%)$ & $3(4 \%)$ & - & $18(24 \%)$ & $3(4 \%)$ & $2(3 \%)$ \\
\hline
\end{tabular}

Abbreviations: $\mathrm{CDI}=\mathrm{DTIC}$-based chemotherapy; $\mathrm{CTI}=\mathrm{TMZ}$-based chemotherapy; DTIC = Dacarbazine; TMZ = Temozolomide. Data are N (\%).

patients. Weber et al (2005), although declaring the analysis was not planned in advance, reported a significant reduction from 33 to $6 \%$ in CNS failure, as first site of recurrence, comparing a TMZ bio-chemotherapy combination with patients previously treated with a DTIC bio-chemotherapy regimen. Instead, when a brain imaging follow-up was planned, as in the phase II trial by Gonzalez Cao et al (2006) where brain MRI was carried out every 3 months, the CNS failure rate observed with a TMZ schedule was similar to that observed with a DTIC regimen. A high percentage of CNS recurrences ( 10 out of 28 patients) has also recently been reported by Wierzbicka-Hainaut et al (2010), in a phase II study with cisplatin and TMZ. Besides the drawbacks of being either phase II or retrospective, all these studies seem to indicate that CNS failure is more related to the modality and timing to detect it, than to the regimen used. Moreover, considering or not the early progressions in other visceral sites as competitive with the CNS failures could influence the results.

This study was powered to detect an absolute $18 \%$ reduction of CNS failure as expected from previous phase II studies (Atkins et al, 2002; Paul et al, 2002), therefore we can not exclude that a larger study could be statistically significant. However, in our opinion, the main reason for the inefficacy or low efficacy in preventing or significantly delaying the CNS recurrence is related to the low systemic activity of TMZ and all chemotherapy combinations in metastatic melanoma. Our study highlights that patients who developed CNS metastases did not have a worse prognosis than other patients progressing in other sites and represent $40 \%$ of long-survivors. Therefore, we firmly believe that CNS metastases should not be an exclusion criterion for new investigational studies.

In the early stage of the CNS metastasis process, the BBB is a key point. In established CNS metastases there is disruption and leakiness of the BBB due to hydrostatic pressure, tumour size and ischaemia. Therefore, when the lesions are well established, the specific activity of the drug is crucial to obtain a clinical effect. Different tumour types have different BBB permeability depending on tumour cell expression or secretion of specific molecules (Cordon-Cardo et al, 1990; Toth et al, 1996). Thus, in order to decrease CNS progression in melanoma patients, we need drugs with a greater systemic activity, able to cross the BBB and active in the CNS growing metastatic cells (Gerstner and Fine, 2007). A more successful control of systemic disease with a drug unable to cross the BBB and not effective in CNS metastases, could lead to an increase in the CNS failures (Ono et al, 2009). The increased incidence of CNS metastases in breast cancer patients treated with trastuzumab (Bendell et al, 2003), supports this concept. Considering our findings and all these aspects, we believe that any new drug with some activity in melanoma should be evaluated also for its effect on CNS metastasis incidence. Owing to the high propensity of melanoma cells to metastasise to the brain, drugs unable to reach or ineffective in this site, risk having a limited impact on the clinical course of the disease.

Even if the reliability of our results could be questioned by the small sample size, the global and 1-year incidence of CNS metastases in melanoma patients is not significantly reduced by TMZ in combination with cisplatin and IL-2 vs the same combination with DTIC. We believe that this failure should be ascribed to the low systemic activity of this combination and to the high propensity of melanoma to develop CNS metastases.

\section{ACKNOWLEDGEMENTS}

We thank all the patients who took part in the trial and M Clerico and E Perfetti, Hospital of Biella; R Cavallo, Hospital of Camposampiero; F Zumaglini, Hospital of Ravenna; RR Silva, Hospital of Fabriano; MG Ghi and M Medici, Hospital of Venezia; D Donati and E Raisi, Hospital of Ferrara; A Muggiano, Hospital of Cagliari for their contribution in enrolling and treating the patients. We also thank Denise Kilmartin for data management and her help in editing the paper. We are grateful to the Italian Melanoma Intergroup for covering costs of the study insurance and to the Schering-Plough Corporation for supplying the Temozolomide free of charge for the study. This study was funded by Italian Melanoma Intergroup (IMI).

\section{Disclaimer}

Vanna Chiarion-Sileni and Ruggero Ridolfi are members of the Italian Melanoma Intergroup Board.

\section{REFERENCES}

Atkins MB, Gollob JA, Sosman JA, McDermott DF, Tutin L, Sorokin P, Parker RA, Mier JW (2002) A phase II pilot trial of concurrent biochemotherapy with cisplatin, vinblastine, temozolomide, interleukin 2, and IFN-alpha 2B in patients with metastatic melanoma. Clin Cancer Res 8(10): $3075-3081$
Atkins MB, Lotze MT, Dutcher JP, Fisher RI, Weiss G, Margolin K, Abrams J, Sznol M, Parkinson D, Hawkins M, Paradise C, Kunkel L, Rosenberg SA (1999) High-dose recombinant interleukin 2 therapy for patients with metastatic melanoma: analysis of 270 patients treated between 1985 and 1993. J Clin Oncol 17(7): 2105-2116 
Bafaloukos D, Tsoutsos D, Kalofonos H, Chalkidou S, Panagiotou P, Linardou E, Briassoulis E, Efstathiou E, Polyzos A, Fountzilas G, Christodoulou C, Kouroussis C, Iconomou T, Gogas H (2005) Temozolomide and cisplatin versus temozolomide in patients with advanced melanoma: a randomized phase II study of the Hellenic Cooperative Oncology Group. Ann Oncol 16(6): 950-957

Balch CM, Buzaid AC, Soong SJ, Atkins MB, Cascinelli N, Coit DG, Fleming ID, Gershenwald JE, Houghton Jr A, Kirkwood JM, McMasters KM, Mihm MF, Morton DL, Reintgen DS, Ross MI, Sober A, Thompson JA, Thompson JF (2001) Final version of the American Joint Committee on Cancer staging system for cutaneous melanoma. J Clin Oncol 19(16): $3635-3648$

Barnholtz-Sloan JS, Sloan AE, Davis FG, Vigneau FD, Lai P, Sawaya RE (2004) Incidence proportions of brain metastases in patients diagnosed (1973 to 2001) in the Metropolitan Detroit Cancer Surveillance System. J Clin Oncol 22(14): 2865-2872

Bendell JC, Domchek SM, Burstein HJ, Harris L, Younger J, Kuter I, Bunnell C, Rue M, Gelman R, Winer E (2003) Central nervous system metastases in women who receive trastuzumab-based therapy for metastatic breast carcinoma. Cancer 97(12): 2972-2977

Bhatia S, Tykodi SS, Thompson JA (2009) Treatment of metastatic melanoma: an overview. Oncology (Williston Park) 23(6): 488-496

Britten CD, Rowinsky EK, Baker SD, Agarwala SS, Eckardt JR, Barrington R, Diab SG, Hammond LA, Johnson T, Villalona-Calero M, Fraass U, Statkevich P, Von Hoff DD, Eckhardt SG (1999) A Phase I and pharmacokinetic study of temozolomide and cisplatin in patients with advanced solid malignancies. Clin Cancer Res 5(7): 1629-1637

Cordon-Cardo C, O'Brien JP, Boccia J, Casals D, Bertino JR, Melamed MR (1990) Expression of the multidrug resistance gene product (P-glycoprotein) in human normal and tumor tissues. I Histochem Cytochem 38(9): $1277-1287$

D'Atri S, Graziani G, Lacal PM, Nistico V, Gilberti S, Faraoni I, Watson AJ, Bonmassar E, Margison GP (2000) Attenuation of O(6)-methylguanineDNA methyltransferase activity and mRNA levels by cisplatin and temozolomide in jurkat cells. J Pharmacol Exp Ther 294(2): 664-671

Eton O, Legha SS, Bedikian AY, Lee JJ, Buzaid AC, Hodges C, Ring SE, Papadopoulos NE, Plager C, East MJ, Zhan F, Benjamin RS (2002) Sequential biochemotherapy versus chemotherapy for metastatic melanoma: results from a phase III randomized trial. J Clin Oncol 20(8): 2045-2052

Gerstner ER, Fine RL (2007) Increased permeability of the blood-brain barrier to chemotherapy in metastatic brain tumors: establishing a treatment paradigm. J Clin Oncol 25(16): 2306-2312

Gonzalez Cao M, Malvehy J, Marti R, Conill C, Sanchez M, Martin M, Carrera C, Herrero J, Gascon P, Mellado B, Castel T, Puig S (2006) Biochemotherapy with temozolomide, cisplatin, vinblastine, subcutaneous interleukin-2 and interferon-alpha in patients with metastatic melanoma. Melanoma res 16(1): 59-64

Gray RJ (1988) A class of k-sample tests for comparing the cumulative incidence of a competing risk. Ann Stat 16: 1141-1154

Houghton AN, Coit DG, Daud A, Dilawari RA, Dimaio D, Gollob JA, Haas NB, Halpern A, Johnson TM, Kashani-Sabet M, Kraybill WG, Lange JR, Martini M, Ross MI, Samlowski WE, Sener SF, Tanabe KK, Thompson JA, Trisal V, Urist MM, Walker MJ (2006) Melanoma. J Natl Compr Canc Netw 4(7): $666-684$

Ives NJ, Stowe RL, Lorigan P, Wheatley K (2007) Chemotherapy compared with biochemotherapy for the treatment of metastatic melanoma: a meta-analysis of 18 trials involving 2,621 patients. J Clin Oncol 25(34): $5426-5434$

Middleton MR, Grob JJ, Aaronson N, Fierlbeck G, Tilgen W, Seiter S, Gore M, Aamdal S, Cebon J, Coates A, Dreno B, Henz M, Schadendorf D,
Kapp A, Weiss J, Fraass U, Statkevich P, Muller M, Thatcher N (2000) Randomized phase III study of temozolomide versus dacarbazine in the treatment of patients with advanced metastatic malignant melanoma. $J$ Clin Oncol 18(1): $158-166$

Ono M, Ando M, Yunokawa M, Nakano E, Yonemori K, Matsumoto K, Kouno T, Shimizu C, Tamura K, Katsumata N, Fujiwara Y (2009) Brain metastases in patients who receive trastuzumab-containing chemotherapy for HER2-overexpressing metastatic breast cancer. Int J Clin Oncol 14(1): $48-52$

Paul MJ, Summers Y, Calvert AH, Rustin G, Brampton MH, Thatcher N, Middleton MR (2002) Effect of temozolomide on central nervous system relapse in patients with advanced melanoma. Melanoma res 12(2): $175-178$

Piccioni D, D'Atri S, Papa G, Caravita T, Franchi A, Bonmassar E, Graziani G (1995) Cisplatin increases sensitivity of human leukemic blasts to triazene compounds. J Chemother 7(3): 224-229

Ready N, Aronson F, Wanebo H, Kennedy T (2005) A low rate of central nervous system progression in a phase II trial of outpatient chemobiologic therapy with cisplatin, temozolomide, interleukin-2, and interferon alfa 2-B for metastatic malignant melanoma. Am J Clin Oncol 28(5): $479-484$

Ridolfi R, Chiarion-Sileni V, Guida M, Romanini A, Labianca R, Freschi A, Lo Re G, Nortilli R, Brugnara S, Vitali P, Nanni O (2002) Cisplatin, dacarbazine with or without subcutaneous interleukin-2, and interferon alpha-2b in advanced melanoma outpatients: results from an Italian multicenter phase III randomized clinical trial. J Clin Oncol 20(6): $1600-1607$

Ridolfi R, Romanini A, Sileni VC, Michiara M, Guida M, Biasco G, Poletti P, Amaducci L, Leoni M, Ravaioli A (2004) Temozolomide and interferonalpha in metastatic melanoma: a phase II study of the Italian Melanoma Intergroup. Melanoma res 14(4): 295-299

Ron IG, Sarid D, Ryvo L, Sapir EE, Schneebaum S, Metser U, Asna N, Inbar MJ, Safra T (2006) A biochemotherapy regimen with concurrent administration of cisplatin, vinblastine, temozolomide (Temodal), interferon-alfa and interleukin-2 for metastatic melanoma: a phase II study. Melanoma res 16(1): 65-69

Toth K, Vaughan MM, Peress NS, Slocum HK, Rustum YM (1996) MDR1 P-glycoprotein is expressed by endothelial cells of newly formed capillaries in human gliomas but is not expressed in the neovasculature of other primary tumors. Am J Pathol 149(3): 853-858

Weber RW, O’Day S, Rose M, Deck R, Ames P, Good J, Meyer J, Allen R, Trautvetter S, Timmerman M, Cruickshank S, Cook M, Gonzalez R, Spitler LE (2005) Low-dose outpatient chemobiotherapy with temozolomide, granulocyte-macrophage colony stimulating factor, interferonalpha $2 \mathrm{~b}$, and recombinant interleukin-2 for the treatment of metastatic melanoma. J Clin Oncol 23(35): 8992-9000

Wen PY, Black PM, Loeffler JS (2001) Treatment of metastatic cancer. In Cancer: Principles \& Practice of Oncology DeVita Jr VT, Hellman S, Rosenberg SA (eds) 6th edn, pp 2655-2670. Lippincott, Williams \& Wilkins: Philadelphia, PA

Wierzbicka-Hainaut E, Sassolas B, Mourey L, Guillot B, Bedane C, Guillet G, Tourani JM (2010) Temozolomide and cisplatin combination in naive patients with metastatic cutaneous melanoma: results of a phase II multicenter trial. Melanoma res 20(2): 141-146

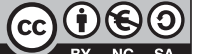

This work is licensed under the Creative Commons Attribution-NonCommercial-Share Alike 3.0 Unported License. To view a copy of this license, visit http://creativecommons. org/licenses/by-nc-sa/3.0/ 